\title{
Kuantum Öğrenme Çevresi Ölçeği Geliştirme Çalışması ${ }^{1}$
}

\author{
Araş. Gör. Dr.Mehmet Altın \\ Aydın Adnan Menderes Üniversitesi-Türkiye \\ mehmet.altin@adu.edu.tr
}

\author{
Prof. Dr. Asuman Seda Saracaloğlu \\ Aydın Adnan Menderes Üniversitesi-Türkiye \\ sedasaracal@gmail.com
}

\begin{abstract}
Özet:
Kuantum öğrenme, başarısı ögretimde ispatlanmış teori ve yaklaşımlarının etkileşimli bileşimi olarak tanımlanmaktadır. Öğrenme ortamlarının kuantum öğrenme modeline uygun bir şekilde düzenlenmesi önemli görülmektedir. Bu çalışmanın amacı, bir sınıfın kuantum öğrenme çevresine uygunluğunu ölçebilen bir ölçme aracı geliştirmektir. Kuantum öğrenme modeline uygun şekilde 7. sınıf öğrencilerine uygulanan programa ilişkin nitel veriler incelendiğinde kuantum öğrenme çevresine dair verilere rastlanmıştır. Verilerin incelenmesinden ortaya çıkan kodlar ve literatür taraması kullanılarak kuantum öğrenme çevresine ilişkin bir madde havuzu oluşturulmuştur. Oluşturulan madde havuzu üzerinde gerçekleştirilen güvenirlik ve geçerlilik incelemeleri sonunda toplam 6 boyut ve 26 maddeden meydana gelen Kuantum Öğrenme Çevresi Ölçeği ortaya çıkmıştır. Geliştirilmiş olan ölçeğin RMSEA değeri.04, CFI değeri .93, IFI değeri ise .93 ve SRMR değeri .049'dur. Ölçeğin iç tutarlllık için katsayısı ise .93'tür.
\end{abstract}

Anahtar kelimeler: Öğrenme çevresi, Kuantum öğrenme, Ölçek geliştirme

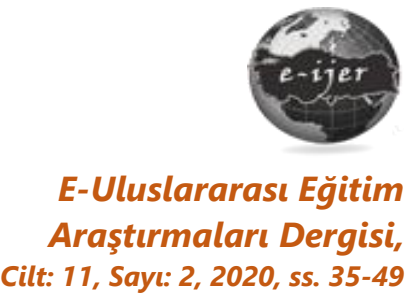

DOI: 10.19160/ijer.742471

\section{Önerilen Atıf}

Altın, M. \&. Saracaloğlu, A. S. (2020). Kuantum Öğrenme Çevresi Ölçeği Geliştirme Çalışması, E-Uluslararası Eğitim Araştırmaları Dergisi, Cilt: 11, Sayı: 2, 2020, ss. 35-49, DOI: 10.19160/ijer.742471

\footnotetext{
${ }^{1}$ Makale ikinci yazarın danışmanlığında birinci yazarın hazırladığı doktora tezinin bir kısmından yapılmıştır ve 26-28 Ekim 2018 tarihinde düzenlenen Uluslararası Necatibey Eğitim ve Sosyal Bilimler Araştırmaları Kongresi (Unesak-2018)'nde sözlü bildiri olarak sunulmuştur.
} 


\section{Giriş}

"Endüstri 4.0" olarak tanımlanan teknoloji alanındaki gelişmeler insan yaşamında birçok değişim yaratmıştır (Öztemel, 2018). Bu değişime ayak uydurmak amacıyla bilgiye daha hızı ve etkili ulaşma konusunda becerilere sahip ve bu becerileri yaşamları boyunca farklı alanlarda kullanan bireylerin sayısının artması amacıyla öğretim esnasında öğrenene önem veren öğrenim modellerine yönelik daha fazla çalışma yapılması intiyaç haline gelmiştir (Hanbay, 2009). Bireylerin bilişsel, duyuşsal ve psiko-motor becerilerinin gelişmekte olduğu özellikle ilk ve orta eğitim kademelerinde öğrenim modellerinin önemi oldukça büyüktür. Farklı eğitim kademelerinde başvurulabilecek modellerden biri de kuantum öğrenme modelidir.

Kuantum, enerjiyi ışığa çeviren etkileşim olarak tanımlanmaktadır. Bütün yaşam bir enerjidir. Kuantum fiziğinde iyi bilinen formüllerden biri, "maddenin kütlesi" çarpı "ışık hızının karesi" eşittir "enerji"dir, $\left(E=m c^{2}\right)$. Kuantum öğrenme, başarısı eğitimde ispatlanmış teori ve yaklaşımlarının etkileşimli bileşimdir ve her öğrenme stiline sahip her yaş grubundaki öğrenenlere ideal bir model olarak ifade edilebilir (DePorter ve Hernacki, 1992).

Kuantum temelli bir öğretim programında izlenecek yol; önceden belirlenmemekte, bireylerin ihtiyaçlarına, ilgilerine ve öğrenme biçemlerine göre esnemektedir. Kuantum teorisini içselleştiren bir öğretim programı, zihin ve deney arasında oluşturulacak olan bir bağlantıyı temel almalıdır. Zihinsel oluşum, duygusal ve duyusal oluşum sayesinde farklı zeka türlerine katkı sağlar. Bu yüzden böyle bir program bilişin yanı sıra duyguya, düşünceye, sezgiye ve yaratıcılığa da yer vermektedir. Türkiye'de 2004 senesinde reform sayılacak değişimlerle, kuantum teorisi bilimsel felsefe olarak eğitim programlarına girmiş̧tir. Bu yüzden, kuantum felsefesinde temellendirilen program; bütüncül, yaratıcı ve eleştirel düşünen, çoklu bakış açısına sahip bireylerin yetiştirilmesini amaçlamaktadır (Ekici, 2013). Kanadlı, Ünal ve Karakuş (2015) kuantum öğrenme modeline uygun biçimde düzenlenmiş ortamların akademik başarıyı olumlu yönde etkilediğini belirtmiştir. Suryani (2013) kuantum öğrenme modelinin tarih öğreniminde başarı üzerindeki etkisini incelemiş; kuantum öğrenme modelinin tarih öğreniminde başarıyı artırdığı ve tarihe ilgisi olan öğrencilerin tarih başarısının da yüksek olduğu sonucuna ulaşılmıştır. Trice (2012), kuantum öğrenme modelinin derste uygulanmasının öğrencilerin okuma ve dil becerilerindeki akademik başarısı ve öğrenme kalıcılığı üzerindeki etkisini incelemiş; araştırması sonunda, kuantum öğrenme modelinin okuma ve dil becerilerindeki akademik başarısı ve öğrenmenin kalıcılığı üzerinde olumlu etkisi olduğu sonucuna ulaşılmıştır. Yapılan araştırmalarda öğrenme ortamlarının kuantum öğrenme modeline uygun bir şekilde düzenlenmesi önemli görülmektedir. Bu çalışmanın amacı, bir sınıfın kuantum öğrenme çevresine uygunluğunu ölçebilen bir ölçme aracı geliştirmektir.

Kuantum öğrenmede öğrenenlerin dikkatlerini çeken ve onlara güven hissi veren yaklaşımlar önemli yer tutar. Etkili sınıf yönetiminde başvurulan yaklaşımlar, dikkat toplama teknikleri ve öğrenenlerin öğrenme etkinliklerine etkili katılımlarında motivasyonun sağlanması kuantum öğrenme çevresinde yer alan diğer değişkenlerdir. Kuantum öğrenmede ilk olarak öğrenenlerin deneyimleri ile içerik arasında bağ kurulur (Deporter ve Hernacki, 1992; Given ve Deporter, 2015).

Beyin, çevresinden sürekli uyaran algılamaktadır. Kuantum öğrenme, bazı faktörlere odaklanarak aktif öğrenimi destekleyen fırsatlar yaratır; oturma düzeni, merak uyandıracak ve içeriği güçlendirecek çevresel faktörler, ışıklandırma, sıcaklık, düzen/temizlik, durum yönetimini ve ilgi merkezini destekleyecek müzik kullanılması gibi. Çevreyle ilgili bu özellikler üç başlık altında toplanmıştır (Deporter ve Hernacki, 1992; Given ve Deporter, 2015): 
Tablo 1:

Kuantum öğrenme çevresini oluşturan öğeler

\begin{tabular}{|c|c|c|}
\hline Öğe & Açıklama & Koşullar \\
\hline Sinıf & $\begin{array}{l}\text { Öğrenenlerden oluşan bir ortamda kişisel arası etkileşim } \\
\text { ve işbirliği ile ilgilidir. Öğrenenin aktif olması amaçlanır. }\end{array}$ & $\begin{array}{l}\text { Öğrencilerin rahat edebileceği sınıf düzeni } \\
\text { Sınıfın yeterince aydınlık olması } \\
\text { Görsel ögeler } \\
\text { Müzik }\end{array}$ \\
\hline Atmosfer & $\begin{array}{l}\text { Öğrenenlerin bilişsel, duyuşsal ve sosyal riskler } \\
\text { alabilecekleri güvene sahip oldukları olumlu ve } \\
\text { hoşgörülü bir sınıf iklimi ile ilgilidir. }\end{array}$ & $\begin{array}{l}\text { Olumlu hava } \\
\text { Güven verici ortam } \\
\text { Destek veren bireyler } \\
\text { Merak uyandırıcı } \\
\text { Eğlenceli }\end{array}$ \\
\hline Fiziksel & $\begin{array}{l}\text { Sınıfın fiziki durumunu destekleyen ve öğrenmeyi } \\
\text { zenginleştiren bir alan amaçlanmaktadır. }\end{array}$ & $\begin{array}{l}\text { Hareketlilik } \\
\text { Farklı etkinliklere geçiş } \\
\text { Oyunlar } \\
\text { Birlikte çalışma } \\
\text { Derse katılım } \\
\text { Etkinlikler arası mola }\end{array}$ \\
\hline
\end{tabular}

Kuantum öğrenme için öncelikle ortamın kuantum öğrenmeye uygun hale getirilmesi gerekmektedir (Deporter ve Hernacki, 1992):

1- $\quad$ Rahat ve dinlendirici bir atmosfer yaratılmalı.

2- $\quad$ Rahatlatıcı, uyarıcı ve odaklayıcı müzik kullanılmalı.

3- $\quad$ Farklı müzik türleriyle farklı havalar yaratılmalı.

4- Olumlu tutumu sürdürmek için görsel hatırlatıcılar kullanılmalı.

5- $\quad$ Öğrenenlerin çevresiyle etkileşim içinde olabileceği bir ortam oluşturulmalı.

Kuantum öğrenme için hem fiziksel hem de duygusal olarak uygun bir çevre yaratılmalıdır. Yapılması gerekenler bir listede kontrol edilmelidir (Deporter ve Hernacki, 1992).

\begin{tabular}{lc}
\hline \multicolumn{1}{c}{ Kuantum Öğrenme Çevresinin Ögeleri } & Kontrol \\
\hline Mobilya- tipi ve düzenlemesi & $\square$ \\
Işıklandırma & $\square$ \\
Müzik & $\square$ \\
Görseller-posterler, resimler, bülten tahtası & $\square$ \\
Gereçlerin yerleşimi & $\square$ \\
Sıcaklık & $\square$ \\
Bitkiler & $\square$ \\
Rahatlık & $\square$ \\
Genel hava & $\square$ \\
\hline
\end{tabular}

Şekil 1. Kuantum öğrenme çevresi için kontrol listesi (Deporter ve Hernacki, 1992)

Motivasyonun kolaylıkla sağlanacağı ortamlar düşünülmelidir. Bu bir okul sırası, bir çalışma odası ya da özel bir yer olabilir. Bazı öğrenciler düzensiz alanları sever. Mutfak masasında çalışırlar, rahat bir koltukta kitap okurlar ya da her şeyin gözlerinin önünde olduğu bir alanda/masada çalışmayı severler. Her öğrenen kendi enerjisini en üst seviyeye çıkarabileceği ve çalışmasına odaklanabileceği alanlarda çalışmayı isterler. Bu yüzden sınıf ortamı da bu öğrenenlerin rahat edebileceği biçimde düzenlenmelidir (Deporter, 2006; Deporter ve Hernacki, 1992).

Kuantum öğrenme çevresinde müzik çok önemli bir yere sahiptir. Zihin yoran çalışmalarda, nabız ve kan basıncı artmaktadır. Beyindeki dalgalar, hızlanır ve kaslar sıkışır. Rahatlama ve meditasyon esnasında, nabız ve kan basıncı düşer ve kaslar gevşer. Normalde tamamen rahatlandığında dikkat toplanması veya dikkatle çalışıldığında rahat olunması zor olur. Zorlayıcı zihinsel etkinlikler gerçekleştirilirken öğrenenleri rahatlatmanın yolları aranmıştır. Deneysel çalışmaların ardından çözümün müzikte olduğu sonucuna ulaşılmıştır. Müzikle 
başlatılmış rahatlama, zihni açık tutmakta ve odaklamayı sağlamaktadır. Bu duruma olanak sağlayan en etkili müziğin, Bach, Handel, Pachelbel ve Vivaldi'nin müzikleri gibi barok müziklerin olduğu ileri sürülmüştür (Deporter, 2006; Deporter, Reardon ve Singer-Nourie, 1999).

Eğitimin iyileştirilmesi ve amaçlara ulaşılması için başarısı kanıtlanmış modellerin öğrenme ortamlarında uygulanmasına intiyaç vardır. Model uygulanmasında önemli ögelerden biri dersliklerde modellere uygun çevrenin oluşturulmasıdır. Bu nedenle öğrenme çevrelerin herhangi bir modele uygunluğunun nasıl ölçülebileceğine dair sorunlar ortaya çıkmaktadır. Alan yazın incelendiğinde modellere uygun öğrenme çevreleriyle ilgili çalışmalara ihtiyaç olduğu görülmektedir. Bu çalışmayla bir sınıfın kuantum öğrenme çevresine uygunluğunu ölçebilen bir araç geliştirilmesi ve böylelikle alan yazına katkı sağlanması amaçlanmıştır.

\section{YÖNTEM}

Bu çalışmanın amacı, bir sınıfın kuantum öğrenme çevresine uygunluğunu ölçebilen bir ölçme aracı geliştirmektir. Ölçek hazırlanırken DeVellis (2003) tarafından önerilen işlemler gerçekleştirilmiştir. Ölçeğin geliştirilmesine ilişkin süreçte sırasıyla madde havuzunun hazırlanması, kapsam geçerliği için uzman görüşü alma çalışması, deneme uygulaması, yapı geçerliği ve güvenirlik analizleri gerçekleştirilmiştir.

\section{Çalışma Grubu:}

2017-2018 eğitim-öğretim yılında gerçekleştirilen çalışmanın madde havuzu hazırlama sürecine 7. sınıfta okuyan 36 öğrenci kuantum öğrenme modeline göre tasarlanan programa dair görüşleri, pilot çalışması sürecine 7. sınıfta okuyan 28 öğrenci taslak ölçme aracına dair görüşleri ve yapı geçerliliği çalışmasına 7. sınıfta okuyan 476 öğrenci ölçekleri doldurarak katıım sağlamıştır. Öğrencilerin derslere olan ilgilerinin ergenliğe geçiş dönemlerinde azalmasından (Altın ve Saracaloğlu, 2018) dolayı bu çalışmaya en çok ortaokulun son iki senesinde ihtiyaç duyulduğu düşünülmüştür. Sekizinci sınıfların araştırmaya dahil edilmemesinin sebebi ise liseye geçiş sınavından dolayı öğrencilerin o sınava odaklanıp pilot uygulama için isteksiz davranabilecekleri ve sekizinci sınıflar üzerine deneysel bir çalışmaya izin verilme sürecinde sıkıntı yaşanabileceği düşünülmesidir.

\section{Madde Havuzunun Hazırlanması:}

Aydın ilinde orta sosyo-ekonomik düzey bölgesinde bir ortaokulun yedinci sınıfında kuantum öğrenme modeline uygun biçimde düzenlenen programın uygulanışı esnasında çeşitleme stratejisiyle veriler toplanmıştır. Çeşitleme stratejisi, farklı veri kaynakları, farklı veri toplama ve analiz yöntemleri kullanarak araştırma sonuçlarının inandırıcılığını arttırmaya yönelik çabaların bütünüdür (Yıldırım ve Şimşek, 2008). Çeşitlemede kullanılan veri toplama teknikleri; gözlem, doküman incelemesi ve görüşmedir. Program uygulanırken dersin öğretmeni ve araştırmacı gözlemlerini saha notlarına aktarmışlardır. Saha notları, sınıfta gerçekleşen eylemlerin yazılı olarak kayda geçirilmesidir (Johnson, 2015). Her ders sonunda çalışma grubundaki öğrencilerin o dersle ilgili düşüncelerini yazdıkları kayıt defterleri olmuştur; bu defterler araştırmanın doküman incelemesi kısmını oluşturmuştur. Kayıt defterleri, katılımcıların düşüncelerini ve değerlendirmelerini aktardıkları günlüklerdir (Johnson, 2015). Programın uygulanmasından sonra çalışma grubunda puanlama anahtarında en yüksek, orta ve en düşük puan alan üçer öğrenci gruplarından gönüllü olanlarla görüşmeler yapılmıştır. Görüşme soruları çalışma grubundaki öğrencilerin bulundukları gruba uygulanan programa yönelik onların algı ve duygularını belirlemeye yönelik olmuştur. Özellikle kuantum öğrenme çevresini oluşturan ögelerin öğrenciler üzerindeki etkisine dair ifadelere rastlanmıştır:

- "tahtaların üstünde sert bir yere oturmaktansa yumuşak ve rahat bir yere oturmak çok güzel" (görüşme) 
- "(müzik hakkında) bence güzeldi kendimi değişik ama mutlu hissettim" (görüşme)

- "Bugün çok fazla hareket ettik, eğlenceli geçti" (günlük)

- "(gizil öğrenme hakkında) bu fikri sevdim; çünkü nadiren de olsa bazı kelimeleri öğreniyorum" (görüşme)

- "Birlikte çalışmaktan daha fazla hoşlanıyorlar." (saha notu)

- "(duvarlara asılan motive edici sözler hakkında) gayet azim verici" (görüşme)

- "Daha fazla işbirliği içerisine giriyorlar" (saha notu)

- "Bitkiler sınıfımıza daha güzel ve hoş bir görüntü kattı" (günlük)

- "(Kapı süsü ve paspas hakkında) sınıfa birazcık ev havası katıyor" (görüşme)

Elde edilen verilerin analizinden oraya çıkan kodlardan yola çıkarak ve alan yazını tarayarak kuantum öğrenme çevresine yönelik 79 maddelik bir havuz oluşturulmuştur.

\section{Madde Havuzunun Uzman Görüşü Çalışmaları:}

Oluşturulan havuz, kapsam geçerliğinin sağlanması amacıyla görüşlerini almak üzere on uzmana iletilmiştir. Uzmanlardan ikisi kuantum öğrenme ile çalışmalar yapmış olan toplam sekiz program geliştirme ve öğretim alanında öğretim elemanı, biri ölçme ve değerlendirme alanında öğretim elemanı ve biri Türkçe öğretimi alanında öğretim elemanıdır. Uzman görüşü sonrası değişen maddeler Tablo 2'de verilmektedir.

\section{Tablo 2:}

\section{Uzman Görüşü Sonrası Değişen Maddeler}

\begin{tabular}{|c|c|c|}
\hline No & Uzman Görüşü Öncesi & Uzman Görüşü Sonrası \\
\hline 1 & Öğretmenler, öğrencilere olumlu davranış gösterir. & $\begin{array}{l}\text { Öğretmenler, öğrencilere karşı olumlu davranış } \\
\text { gösterirler. }\end{array}$ \\
\hline 5 & Öğretmenler, öğrencilere güvenir. & Öğretmenler, öğrencilerin başarılı olacağına inanırlar. \\
\hline 13 & Sınıfta, öğrencileri cesaretlendirici görseller vardır. & Sınıfta, öğrencileri cesaretlendirici görsel ögeler vardır. \\
\hline 16 & Sınıfta, öğrencileri motive edici görseller vardır. & Sınıfta, öğrencileri motive edici görsel ögeler vardır. \\
\hline 19 & Sınıfta yapılan çalışmalar sergilenir. & Başarılı çalışmalar sergilenir. \\
\hline 23 & Öğretmenler, görünümlerine özen gösterir. & Öğretmenler, dış görünüşlerine özen gösterirler. \\
\hline 25 & $\begin{array}{l}\text { Öğretmenler, öğrencileri başarabilecekleri konusunda } \\
\text { cesaretlendirir. }\end{array}$ & $\begin{array}{l}\text { Öğretmenler, öğrencileri bir görevi başarabilecekleri } \\
\text { konusunda cesaretlendirirler. }\end{array}$ \\
\hline 29 & Öğretmenler, yumuşak tonda konuşur. & Öğretmenler, yumuşak bir ses tonuyla konuşurlar. \\
\hline 30 & Ders esnasında rahatlatııı müzik çalar. & Ders esnasında rahatlatıcı müzik çalınır. \\
\hline 35 & Derslerde rahat davranılan bir atmosfer vardır. & Sınıf atmosferi öğrencileri rahatlatır. \\
\hline 38 & Ders çalışırken odaklayıcı müzik çalar. & $\begin{array}{l}\text { Sınıfta ders çalışırken odaklanmaya yardımcı olan } \\
\text { müzik çalınır. }\end{array}$ \\
\hline 45 & Derslerde öğrenciler aktiftir. & Öğrenciler derslerde aktiftirler. \\
\hline 47 & Sınıfta öğrenciler uyum içerisindedir. & Öğrenciler, sınıfta uyum içerisindedirler. \\
\hline 48 & Sınıfta çalışılan konuyla ilgili materyaller vardır. & Sınıfta çalışılan konuyla ilgili araç ve gereçler vardır. \\
\hline 52 & Sınıfta çalışılan konuyla ilgili görseller vardır. & Sınıfta çalışılan konuyla ilgili görsel ögeler vardır. \\
\hline 59 & $\begin{array}{l}\text { Öğretmenler, öğrencilerin derse katılabilecekleri } \\
\text { fırsatlar sunar. }\end{array}$ & $\begin{array}{l}\text { Öğretmenler, öğrencilerin derse katılabilecekleri } \\
\text { fırsatlar oluştururlar. }\end{array}$ \\
\hline 64 & Derslerde öğrenciler yardımlaşabilir. & Öğrenciler derslerde yardımlaşabilirler. \\
\hline 66 & Derste öğrenciler hata yapmaktan korkmaz. & Öğrenciler derste hata yapmaktan korkmazlar. \\
\hline 67 & Etkinliklerde öğrenciler birlikte hareket edebilir. & Öğrenciler etkinliklerde birlikte hareket edebilirler. \\
\hline 75 & Sınıfta renkli materyaller vardır. & Sınıfta renkli araç ve gereçler vardır. \\
\hline 77 & Etkinlikler arasında molalar vardır. & Etkinlikler arasında kısa süreli molalar vardır. \\
\hline
\end{tabular}

Uzman görüşü sonrası toplam 21 madde özellikle uygulama yapılacak olan katılımcıların maddeleri daha iyi anlayabilmeleri ve maddelerin ölçme aracını daha iyi temsil edebilmesi için değiştirilmiştir.

\section{Ölçeğin Pilot Çalışması:}

Uzmanlardan gelen dönütler doğrultusunda madde havuzu şekillendirilmiş ve denemelik ölçeğin pilot uygulaması bir ortaokulun 7. sınıfında öğrenim gören 28 öğrencinin katılımı ile yapılmıştır. Madde tepki ifadelerinin sonraki sayfaya da eklenmesi gerektiği, öğrencilerin ölçeği 
doldururken sürekli sayfa çevirmek zorunda kaldıkları belirtilmiştir. Pilot uygulama öncesi ve sonrasında değişen maddelere ilişkin madde havuzu Tablo 3'te verilmektedir.

Tablo 3:

Pilot Uygulama Sonrası Değişen Maddeler

\begin{tabular}{cll}
\hline No & \multicolumn{1}{c}{ Pilot Uygulama Öncesi } & \multicolumn{1}{c}{ Pilot Uygulama Sonrası } \\
\hline 2 & Sınıf, renklidir. & Sınıf, rengarenktir. \\
\hline 14 & Derslerde endişe verici bir atmosfer vardır. & Derslerde öğrenciler endişeli hisseder. \\
\hline 16 & Sınıfta, öğrencileri motive edici görsel ögeler vardır. & $\begin{array}{l}\text { Sınıfta, öğrencileri motive edici afişler, posterler vb. } \\
\text { vardır. }\end{array}$ \\
\hline 28 & Sınıfta sıralar "U" düzenindedir. & $\begin{array}{l}\text { Sınıftaki sıralar bütün öğrencilerin tahtayı ve öğretmeni } \\
\text { rahatlıkla görebileceği biçimde düzenlenmiştir. }\end{array}$ \\
\hline 48 & Sınıfta çalışılan konuyla ilgili materyaller vardır. & Sınıfta çalışılan konuyla ilgili araç ve gereçler vardır. \\
\hline 55 & Sınıfta sıralar küme düzenindedir. & $\begin{array}{l}\text { Sınıftaki sıralar öğrencilerin birlikte çalışabileceği biçimde } \\
\text { düzenlenmiştir. }\end{array}$ \\
\hline
\end{tabular}

Pilot uygulama sonrası toplam 6 madde katılımcıların daha iyi anlayabilecekleri biçimde düzenlenmiştir.

\section{BULGULAR}

Bu bölümde "Kuantum Öğrenme Çevresi Ölçeği"nin geliştirilmesi amacıyla pilot uygulama sonrası gerçekleştirilen geçerlik ve güvenirlik çalışmalarına yer verilmiş̧ir.

\section{1. Ölçeğin Geçerlik Çalışması:}

Taslak ölçme aracının yapı geçerliğinin incelenmesi için veri toplamak amacıyla iki orta sosyo-ekonomik düzey ortaokulun 7. sınıflarında öğrenim gören toplam 476 öğrenciye ulaşılmıştır. Yapı geçerliği çalışması için 476 öğrenciden elde edilen veriler kullanılmıştır.

\section{Açımlayıcı Faktör Analizi:}

Yapı geçerliği çalışmasında ilk olarak açımlayıcı faktör analizi uygulanmıştır. Faktör analizi için varsayımların kontrolü işlemi gerçekleştirilmiştir. Öncelikle mahalanobis uzaklığına bakılarak uç değerlere sahip toplam 16 veri setten çıkartılarak normallik sağlanmıştır. Kalan veriler incelendiğinde normal Q-Q grafiğinde gerçekleşen değerler ile beklenen değerlerin 45 derecelik doğruya yakın dağıldıkları belirlenmiştir. Bunun yanı sıra, eğiliminden arındırılmış Q-Q grafiğinde toplanan verilerin yatay sıfır çizgisi civarında rastgele dağılım sergilediklerinden dolayı verilerin normal dağıldığı (Büyüköztürk, 2012) söylenebilir.

Çalışma grubundan elde edilen verilerin açımlayıcı faktör analizine uygun olup olmadığı belirlemek için Kaiser-Meyer-Olkin (KMO) testi gerçekleştirilmiş ve veri setinin faktörleştirilebileceğine karar verilmiştir $(\mathrm{KMO}=.87)$. Ayrıca gerçekleştirilen Bartlett küresellik testi ile maddeler arası ilişkilerin olduğu matrisin, ilişkiler olmadığı birim matristen farklı olduğu görülmüştür $(p<.001)$. Anti-imaj korelasyon matrisinin her bir maddenin faktör çözümlemesi içinde kalıp kalmamasına karar verilmesi için sunduğu ölçütler incelenmiştir. 18. madde hariç tüm madde değerlerin $.5^{\prime}$ in üzerinde olduğu görülmüştür. Bu yüzden 18 . madde ölçekten çıkartılıp analize devam edilmiştir.

Açımlayıcı faktör analizi yöntemi olarak en çok kullanılan (Velicer ve Jackson, 1990) yöntemlerden temel bileşenler analizi kullanılmıştır. Faktör yükü alt sınıı olarak .33 belirlenmiştir. Analiz ilk olarak dördü birer maddeden oluşan 11 boyut önermiştir. Yedi maddenin ise iki faktörle arasındaki ilişki düzeyinin birbirine çok yakın olduğu görülmüştür. Bileşenler matrisine bakıldığında 58 maddenin birinci faktör yük değerlerinin .335 ve üzerinde olduğu görülmüştür. Döndürme öncesi bu faktörün açıkladığı varyans \%22.97'dir. Ölçeğin diğer faktörlerinin belirginleştirilmesi için yapılan madde çıkarma işlemleri ve döndürmeler sonunda 6 boyut ve 26 maddeden oluşan Kuantum Öğrenme Çevresi Ölçeği'ne ulaşılmıştır. Ulaşılan ölçeğin maddeleri 
arası ilişkileri korelasyon matrisinde incelendiğinde, aralarında kabul edilebilir ilişkinin ( $r>3)$ olduğu maddelerin oldukça fazla olduğu görülmüştür. Ayrıca matrisin determinantının .002 olduğu görülmüştür. Bu da faktör çözümlemesinin mümkün olabileceğini göstermektedir (Determinant>.0001). Maddeler arası çoklu eşdoğrusallık da ( $r>.9$ olan maddeler) gözlenmemektedir.

Tablo 4:

Açımlayıcı Faktör Analizi Sonucunda Maddelere ilişkin Elde Edilen Bulgular

\begin{tabular}{|c|c|c|c|c|c|c|c|c|}
\hline$\frac{\frac{1}{\pi}}{\frac{\pi}{2}}$ & $\begin{array}{c}\text { Madde } \\
\text { Havuzu } \\
\text { No }\end{array}$ & F1 & $\mathbf{F 2}$ & F3 & F4 & F5 & F6 & \\
\hline \multirow{5}{*}{ 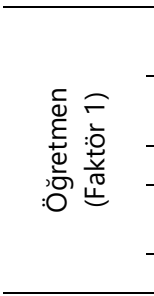 } & Madde 25 & .74 & & & & & & $\begin{array}{l}\text { Öğretmenler, öğrencileri bir görevi } \\
\text { başarabilecekleri konusunda cesaretlendirirler. }\end{array}$ \\
\hline & Madde 5 & .71 & & & & & & $\begin{array}{l}\text { Öğretmenler, öğrencilerin başarılı olacağına } \\
\text { inanırlar. }\end{array}$ \\
\hline & Madde 39 & .68 & & & & & & Öğretmenler, öğrencileri cesaretlendirirler. \\
\hline & Madde 1 & .66 & & & & & & $\begin{array}{l}\text { Öğretmenler, öğrencilere karşı olumlu davranış } \\
\text { gösterirler. }\end{array}$ \\
\hline & Madde 8 & .56 & & & & & & Öğretmenler, öğrencileri güvende hissettirirler. \\
\hline \multirow{5}{*}{ 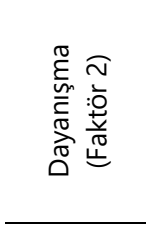 } & Madde 49 & & .69 & & & & & Çalışmalarda başarılı olan öğrenciler alkışlanır. \\
\hline & Madde 50 & & .64 & & & & & Etkinliklerde öğrenciler arasında işbirliği vardır. \\
\hline & Madde 67 & & .63 & & & & & $\begin{array}{l}\text { Öğrenciler etkinliklerde birlikte hareket } \\
\text { edebilirler. }\end{array}$ \\
\hline & Madde 58 & & .59 & & & & & Öğrenciler birbirlerini destekler. \\
\hline & Madde 64 & & .56 & & & & & Öğrenciler derslerde yardımlaşabilirler. \\
\hline \multirow{5}{*}{ 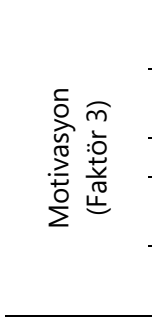 } & Madde 16 & & & .70 & & & & $\begin{array}{l}\text { Sınıfta, öğrencileri motive edici afişler, posterler } \\
\text { vb. vardır. }\end{array}$ \\
\hline & Madde 13 & & & .61 & & .39 & & $\begin{array}{l}\text { Sınıfta, öğrencileri cesaretlendirici görsel ögeler } \\
\text { vardır. }\end{array}$ \\
\hline & Madde 15 & & & .60 & & & & Derslerde oyunlara yer verilir. \\
\hline & Madde 20 & & & .55 & & & & $\begin{array}{l}\text { Öğretmenler, derslerde merak uyandırııı } \\
\text { etkinlikler yaparlar. }\end{array}$ \\
\hline & Madde 12 & & & .53 & & & & $\begin{array}{l}\text { Öğretmenler, öğrencilerin birlikte eğleneceği } \\
\text { etkinlikler yaptırırlar. }\end{array}$ \\
\hline \multirow{4}{*}{ 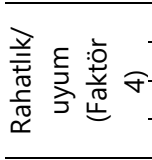 } & Madde 76 & & & & .78 & & & Sinıfta rahat bir ortam vardır. \\
\hline & Madde 46 & & & & .73 & & & Sınıf, rahat ders çalışmaya uygundur. \\
\hline & Madde 35 & & & & .54 & & & Sınıf atmosferi öğrencileri rahatlatır. \\
\hline & Madde 47 & & .38 & & .50 & & & Öğrenciler, sınıfta uyum içerisindedirler. \\
\hline \multirow{4}{*}{ 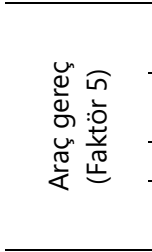 } & Madde 43 & & & & & .68 & & $\begin{array}{l}\text { Sinıfta ihtiyaç olduğunda kullanılan renkli } \\
\text { kalemler vardır. }\end{array}$ \\
\hline & Madde 37 & & & & & .61 & & $\begin{array}{l}\text { Sinıfta ihtiyaç olduğunda başvurabilecek kitaplar } \\
\text { vardır. }\end{array}$ \\
\hline & Madde 75 & & & & & .61 & & Sınıfta renkli araç ve gereçler vardır. \\
\hline & Madde 48 & & & & & .57 & & $\begin{array}{l}\text { Sınıfta çalışılan konuyla ilgili araç ve gereçler } \\
\text { vardır. }\end{array}$ \\
\hline \multirow{3}{*}{ 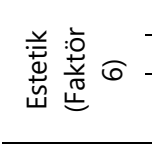 } & Madde 26 & & & & & & .79 & Sınıf kapısı süslüdür. \\
\hline & Madde 30 & & & & & & .69 & Ders esnasında rahatlatıcı müzik çalınır. \\
\hline & Madde 38 & & & & & & .67 & $\begin{array}{l}\text { Sınıfta ders çalışırken odaklanmaya yardımcı olan } \\
\text { müzik çalınır. }\end{array}$ \\
\hline
\end{tabular}

Tablo 4'te görüldüğü üzere faktör yük değerleri .50 ile .79 arasında değişmektedir. Temel bileşenler analizi sonucunda elde edilen faktörün açıkladığı varyans \%51.46'dir.

\section{Doğrulayıcı Faktör Analizi:}

Açımlayıcı faktör analizi sonucu elde edilen modelin yapı geçerliğini test etmek amacıyla doğrulayıcı faktör analizi yapılmıştır. Gizil değişkenlerle ilgili kuramların test edilmesinde kullanılan DFA (Tabachnick ve Fidell, 2015), değişkenler ile boyutlar arasındaki ilişkiyi belirtmektedir. Aynı örneklem üzerinde AFA ve DFA uygulamanın sorun oluşturmadığından (Worthhington ve Whitaker, 2006) DFA'da da 476 öğrenciden elde edilen veriler kullanılmıştır. 
Ayrıca Koyuncu ve Kılıç (2019) açımlayıcı faktör analizi (AFA) ve doğrulayıcı faktör analizinin (DFA) kullanımı üzerine gerçekleştirdikleri doküman incelemesinde 36 çalışmada aynı örneklem üzerinde AFA ve DFA uygulandığını belirtmiştir. Doğrulayıcı faktör analizini yapmak için AMOS programından yararlanılmıştır. Modelde boyut uyumundan elde edilen bulgular Tablo 5 'te verilmektedir.

\section{Tablo 5:}

Uyum Ölçütleri ve DFA'dan Elde Edilen Uyum Indeksleri Değerleri

\begin{tabular}{cllcl}
\hline $\begin{array}{c}\text { Incelenen Uyum } \\
\text { Indeksleri }\end{array}$ & $\begin{array}{c}\text { Mükemmel Uyum } \\
\text { Ölçütleri }\end{array}$ & $\begin{array}{c}\text { Kabul Edilebilir Uyum } \\
\text { Ölçütleri }\end{array}$ & $\begin{array}{c}\text { DFA'dan Elde } \\
\text { Edilen Uyum } \\
\text { İndeksleri }\end{array}$ & $\begin{array}{c}\text { Sonuç } \\
\text { X2/sd }\end{array}$ \\
RMSEA & $0 \leq \chi 2 /$ sd $\leq 2$ & $2 \leq \chi 2 /$ sd $\leq 5$ & 1.67 & Mükemmel Uyum $^{1}$ \\
CFI & $.00 \leq$ RMSEA $\leq .05$ & $.05 \leq \mathrm{RMSEA} \leq .08$ & .04 & Mükemmel Uyum $^{2}$ \\
IFI & $.95 \leq \mathrm{CFI} \leq 1.00$ & $.90 \leq \mathrm{CFI} \leq .95$ & .93 & Kabul Edilebilir Uyum $^{3}$ \\
SRMR & $.00 \leq$ SRMR $\leq .05$ & $.90 \leq \mathrm{IFI} \leq .95$ & .93 & Kabul Edilebilir Uyum $^{3}$ \\
\hline
\end{tabular}

${ }^{1}$ (Kline, 2011), ${ }^{2}$ (Hu ve Bentler, 1999), ${ }^{3}$ (Bentler, 1980)

Tablo 5 incelendiğinde ölçeğin RMSEA değeri .04, CFI değeri .93, IFI değeri .93 ve SRMR değeri .049'dur. RMSEA indeksinde $.05^{\prime}$ e kadar olan değerler ve SRMR'de $.05^{\prime}$ ten küçük değerler modelde mükemmel uyuma (Hu ve Bentler, 1999), CFI ve IFI indekslerinde .9'dan yüksek olan değerler modelde kabul edilebilir uyuma (Bentler, 1980) işaret etmektedir. Ayrıca $X^{2} /$ sd değeri 1.67 çıkmıştır. Bu değerin 0-2 arasında yer alması mükemmel uyum olarak görülmektedir (Kline, 2011). Şekil 2 incelendiğinde modeldeki boyutlar arasındaki ilişki .9'dan büyük olmadığı için değişkenler arasında çoklu bağlantı olmaması varsayımının karşılandığı (Tabachnick ve Fidell, 2015) görülmektedir.

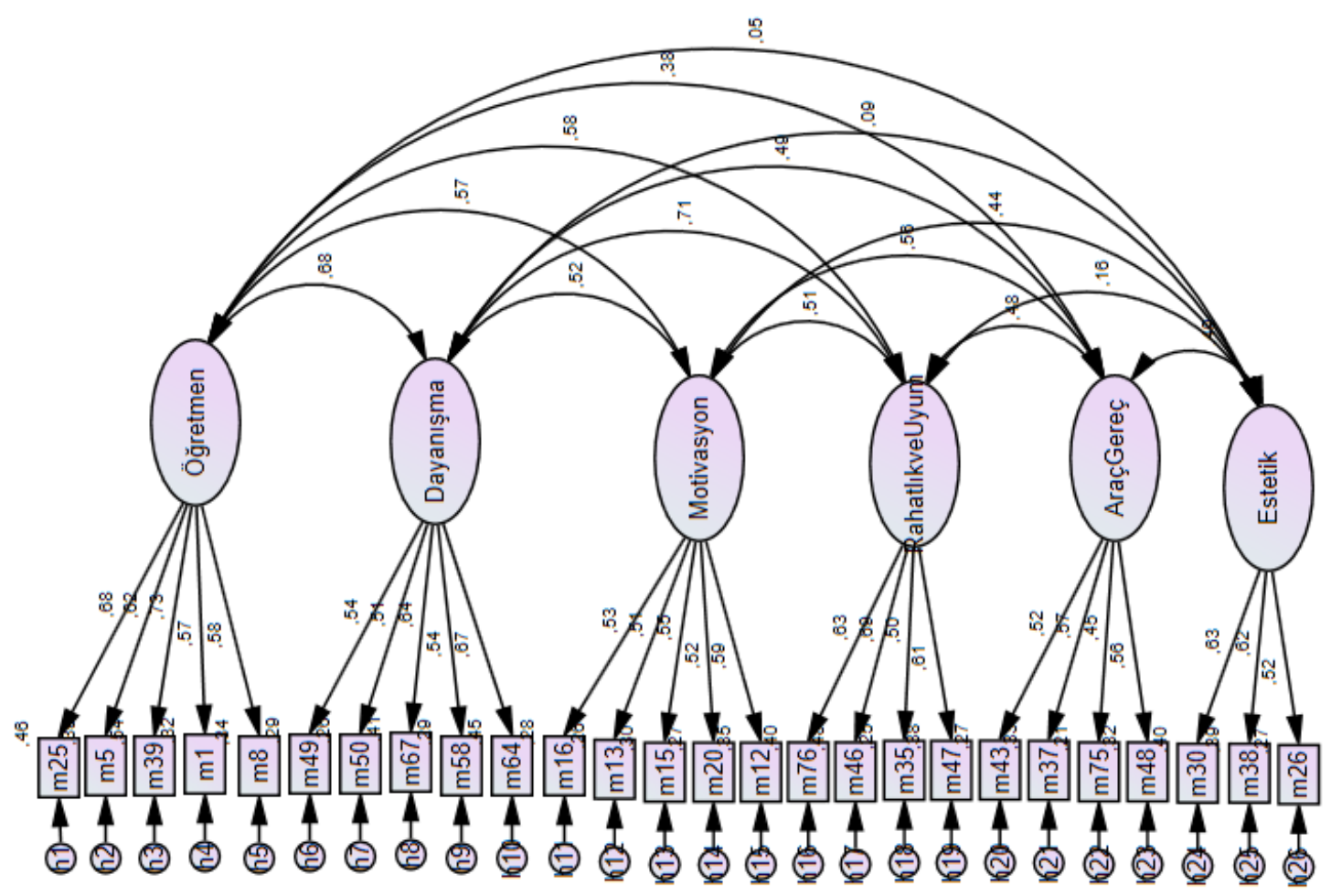

Şekil 2. Kuantum Öğrenme Çevresi Ölçeği Modeli 
Tablo 6:

Doğrulayıcı Faktör Analizi Sonucunda Maddelere Iliş̧kin Elde Edilen Bulgular

\begin{tabular}{|c|c|c|c|c|c|}
\hline Boyutlar & Madde Havuzu No & Yeni Madde No & $\mathbf{t}$ & $\mathbf{X}$ & Ss \\
\hline \multirow{4}{*}{$\begin{array}{l}\text { Öğretmen } \\
\text { (Faktör 1) }\end{array}$} & Madde 25 & 1 & $12.18^{*}$ & 3.73 & 1.16 \\
\hline & Madde 5 & 2 & 12.97* & 4.03 & 1.24 \\
\hline & Madde 1 & 4 & $13.53^{*}$ & 2.93 & 1.19 \\
\hline & Madde 8 & 5 & 13.39* & 2.18 & 1.32 \\
\hline \multirow{4}{*}{$\begin{array}{c}\text { Dayanışma } \\
\text { (Faktör 2) }\end{array}$} & Madde 49 & 6 & $13.53^{*}$ & 2.30 & 1.07 \\
\hline & Madde 67 & 8 & $12.38^{*}$ & 2.79 & 1.27 \\
\hline & Madde 58 & 9 & $13.52^{*}$ & 3.55 & 1.38 \\
\hline & Madde 64 & 10 & $11.84^{*}$ & 1.51 & 1.04 \\
\hline \multirow{2}{*}{$\begin{array}{l}\text { Motivasyon } \\
\text { (Faktör 3) }\end{array}$} & Madde 16 & 11 & $13.12^{*}$ & 1.62 & 1.06 \\
\hline & Madde 13 & 12 & $13.25^{*}$ & 2.54 & 1.28 \\
\hline \multirow{4}{*}{$\begin{array}{c}\text { Rahatlık/ uyum } \\
\text { (Faktör 4) }\end{array}$} & Madde 76 & 16 & $12.10^{*}$ & 2.27 & 1.52 \\
\hline & Madde 46 & 17 & $10.82^{*}$ & 2.97 & 1.40 \\
\hline & Madde 35 & 18 & $13.66^{*}$ & 2.82 & 1.28 \\
\hline & Madde 47 & 19 & $12.39 *$ & 2.32 & 1.32 \\
\hline \multirow{4}{*}{$\begin{array}{c}\text { Araç gereç } \\
\text { (Faktör 5) }\end{array}$} & Madde 43 & 20 & $12.50^{*}$ & 3.19 & 1.40 \\
\hline & Madde 37 & 21 & 11.71* & 2.94 & 1.30 \\
\hline & Madde 75 & 22 & $13.33^{*}$ & 3.02 & 1.31 \\
\hline & Madde 48 & 23 & $11.87^{*}$ & 3.06 & 1.30 \\
\hline $\begin{array}{c}\text { Estetik } \\
\text { (Faktör 6) }\end{array}$ & Madde 26 & 24 & $9.61^{\star}$ & 2.98 & 1.28 \\
\hline
\end{tabular}

${ }^{*} \mathrm{p}<.001$

\section{2. Ölçeğin Güvenirlik Çalışması:}

Geliştirilmiş olan "Kuantum Öğrenme Çevresi Ölçeği"nin güvenirliğinin belirlenmesi için verilerin iç tutarlılık katsayısı hesaplanmıştır. Ölçeğin toplamının iç tutarlılığı için elde edilen bileşik güvenirlik (Raykov, 1997) katsayısı .93'tür. Ölçeğin alt boyutlarının iç tutarlıık katsayısı için Cronbach alfa kullanıımış; "öğretmen" boyutu için .77, dayanışma boyutu için .72, motivasyon boyutu için .67, rahatlık/uyum boyutu için .97, araç-gereç boyutu için .61 ve estetik boyutu için ise .61 katsayısı elde edilmiştir.

\section{Tablo 6.}

Ölçeğin Toplamdaki ve Alt Boyutlardaki iç Tutarlıık Katsayısı

\begin{tabular}{lc}
\hline \multicolumn{1}{c}{ Boyut } & Güvenirlik \\
\hline Ölçek toplamı & .86 \\
Öğretmen & .77 \\
Dayanışma & .72 \\
Motivasyon & .67 \\
Rahatlık/Uyum & .97 \\
Araç-gereç & .61 \\
Estetik & .61 \\
\hline
\end{tabular}




\section{SONUÇ, TARTIŞMA VE ÖNERILER}

Kuantum kavramı; siyah cisim ışıması üzerine gerçekleştirilen araştırmalarda, "enerji öbeği/paketi" olarak tanımlanmıştır. Kuantum, enerjinin ışığa dönüşmesini sağlayan etkileşim olarak öne sürülmüştür. Kuantum öğrenme ise başarısı eğitimde ispatlanmış teori ve yaklaşımlarının etkileşimli bileşimi olarak tanımlanmaktadır. Okullarımızda bütüncül, yaratıcı ve eleştirel düşünen, çoklu bakış açısına sahip bireylerin yetiştirilmesini amaçlanmaktadır. Dolayısıyla öğrenme ortamlarının kuantum öğrenme modeline uygun bir şekilde düzenlenmesi önemli görülmektedir. Bu çalışmanın amacı, bir sınıfın kuantum öğrenme çevresine uygunluğunu ölçebilen bir ölçme aracı geliştirmektir.

Ölçme aracının geliştirme sürecinde 79 maddeden oluşan madde havuzu 476 katılımcıya uygulanmıştır. Ho (akt. Can, 2014) örneklem sayısının madde sayısının 5 katını aşması durumunda analiz sonuçlarının daha kabul edilebilir olduğundan söz etmektedir. Tabacnich ve Fidell (2015), 300 örneklemin iyi olduğunu belirtmiştir. Bu yüzden bu çalışmada katılımcı sayısının yeterli olduğu söylenebilir.

Geliştirilmiş olan ölçeğin RMSEA değeri .04, CFI değeri .93, IFI değeri ise .93 ve SRMR değeri .049'dur. Hu ve Bentler (1999), RMSEA indeksinde .05 ve SRMR indeksinde .049'a kadar olan değerlerin modelde mükemmel uyumun işareti olduğunu belirtmektedir: Ayrıca Bentler (1980)'a göre CFI ve IFI değerlerinin .9'dan yüksel olması modelde kabul edilebilir uyumu göstermektedir. Bunun yanı sıra, X2/sd değeri 1.67 çıkmıştır. Bu değerin 2'den küçük olması modelde mükemmel uyum olduğuna işaret etmektedir (Kline, 2011). Modeldeki boyutlar arasındaki ilişki .9 'dan büyük olmadığı için değişkenler arasında çoklu bağlantı olmaması varsayımının karşılandığı (Tabachnich ve Fidell, 2015) görülmektedir.

Geçerlilik çalışmasının sonunda 6 boyut ve 26 maddeden oluşan Kuantum Öğrenme Çevresi Ölçeği'ne ulaşılmıştır. Ölçeğin iç tutarlıık için katsayısı .93'tür. İç tutarlılık katsayısı .80'den büyük değerlere sahip ölçekler yüksek ölçüde güvenilir olarak kabul edilmektedir (George ve Mallery, 2003). Ölçekte olumsuz ifadede madde bulunmamaktadır. Bu yüzden analizlerde ters kodlama yapılma ihtiyacı bulunmamaktadır. Ölçekten alınabilecek en yüksek puan 130 iken en düşük puan 26 'dır. Ölçeğin uygulanacağı sınıflarda puanların yüksek olması sınıf ortamının kuantum öğrenme çevresine uygun olduğu anlamına gelirken; puanların düşük olması sınıf ortamının kuantum öğrenme çevresine uygun olmadığı anlamına gelecektir.

Geliştirilmiş olan ölçekte veriler ortaokul kademesi 7. öğrencilerinden toplanmıştır. Farklı kademelerde çalışma yapacak araştırmacılara ölçeğin o kademelere göre uyarlama yapmaları önerilebilir. Bu araştırma bir ölçek geliştirme çalışması olup sadece ölçeğin geçerlik ve güvenirliğine ilişkin bulgulara ulaşılmıştır. Bu ölçeği farklı araştırmalarda veri toplama aracı olarak kullanarak yedinci sınıf düzeyindeki sınıflara kuantum öğrenme çevresine ne ölçüde yakın olduğunu belirlemeye yönelik betimsel çalışmalar yapılabilir.

\section{KAYNAKLAR}

Altın, M. ve Saracaloğlu, A. S. (2018). İngilizce öğretimindeki ihtiyacımız nedir? Bir olgu bilim çalışması. Dil Eğitimi ve Araştırmaları Dergisi, 4(2), 137-159.

Bentler, P. M. (1980). Multivariate analysis with latent variables: Causal modeling. Annual Review of Psychology, 31, 419-456.

Büyüköztürk, Ş. (2012). Sosyal Bilimler için Veri Analizi El Kitabı (17. baskı). Ankara: Pegem Akademi. Can, A. (2014). SPSS ile Bilimsel Araştırma Sürecinde Nicel Veri Analizi (2. baskı). Ankara: Pegem Akademi. Deporter, B. (2006). Quantum Success. Learning Forum Publications.

Deporter, B. ve Hernacki, M. (1992). Quantum Learning: Unleashing the Genius in You. NY: Random House. Deporter, B., Reardon, M. ve Singer-Nourie, S. (1999). Quantum Teaching: Orchestrating Student Success. Allyn and Bacon, A Viacom Company. 
DeVellis, R. F. (2014). Ölçek Geliştirme (3. baskı) (Çev. Ed. Totan, T.). Ankara: Nobel Yayınevi.

Ekici, G. (2013). Kuantum öğrenme yaklaşımı, Ekici, G. (Editör) Yeni Öğrenme-Öğretme Yaklaşımları ve Uygulama Örnekleri içinde (462-506). Ankara: Pegem Akademi.

George, D. ve Mallery, P. (2003). SPSS for Windows Step by Step: A Simple Guide and Reference. Boston: Allyn \& Bacon.

Given, B. K. ve Deporter B. (2015). Excellence in Teaching and Learning. Learning Forum Publications.

Hanbay, O. (2009). Kuantum öğrenme temelli öğreterek öğrenme yönteminin ikinci yabancı dil olarak almancanın öğrenilmesine etkisi. Dicle Üniversitesi Ziya Gökalp Eğitim Fakültesi Dergisi, 1 (12), 1727.

Hu, L. T. and Bentler, P. M. (1999). Cutoff criteria for fit indexes in covariance structural analysis: Conventional criteria versus new alternatives. Structural Equation Modeling: A Multidisciplinary Journal, 6, 1-55.

Johnson, A. P. (2015). Eylem araştırması el kitabı (Çev. Uzuner, Y. ve Özten Anay, M.). Ankara: Anı Yayıncılık.

Kanadlı, S., Ünal, K. ve Karakuş, F. (2015). Kuantum öğrenme modelinin akademik başarıya etkisi: Bir metaanaliz çalışması. Mustafa Kemal Üniversitesi Sosyal Bilimler Enstitüsü Dergisi, 12(32), 136-157.

Kline, R. B. (2011). Yapısal eşitlik modellemesinin ilkeleri ve uygulaması (4. basımdan çeviri editörü S. Şen. Ankara: Nobel Akademi Yayıncılık.

Koyuncu, I. ve Kılıç, A. F. (2019). Açımlayııı ve doğrulayıcı faktör analizlerinin kullanımı: bir doküman incelemesi. Eğitim ve Bilim, 44(198), 361-388.

Öztemel, E. (2018). Eğitimde yeni yönelimlerin değerlendirilmesi ve eğitim 4.0. Üniversite Araştırmaları Dergisi, 1(1), 25-30.

Raykov, T. (1997). Estimation of composite reliability for congeneric measures. Applied Psychological Measurement, 21(2), 173-184.

Suryani, N. (2013). Improvement of students' history learning competence through quantum learning model at senior high school in Karanganyar Regency, solo, central java province, Indonesia. Journal of Education and Practice, 4 (14) 55-64.

Tabacnich, B. G. ve Fidell, L. S. (2015). Çok değişkenli istatistiklerin kullanımı (6. baskı) (Çev. ed. Baloğlu, M.). Ankara: Nobel Yayınevi.

Trice, T. Y. (2012). Quantum Learning making progious strides in education. The unpublished doctoral dissertation, Trevecca Nazarene University, School of Education.

Velicer, W. F. ve Jackson, D. N. (1990). Component analysis versus common factor analysis: Some further observations. Multivariate Behavioral Research, 25(1), 97-114.

Yıldırım, A. ve Şimşek, H. (2004). Sosyal Bilimlerde Nitel Araştırma Yöntemleri (4. baskı). Ankara: Seçkin Yayıncılık. 


\section{EK}

\section{Kuantum Öğrenme Çevresi Ölçeği}

\begin{tabular}{|c|c|c|c|c|c|c|}
\hline & iffadeler & 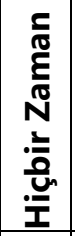 & 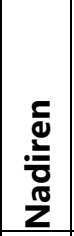 & $\begin{array}{l}\mathbf{\Xi} \\
\mathbb{N} \\
\mathbb{D}\end{array}$ & $\begin{array}{l}\frac{\check{\bar{n}}}{y} \\
\dot{\bar{n}}\end{array}$ & 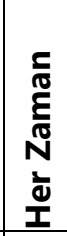 \\
\hline 1 & $\begin{array}{l}\text { Öğretmenler, öğrencileri bir görevi başarabilecekleri konusunda } \\
\text { cesaretlendirirler. }\end{array}$ & & & & & \\
\hline 2 & Öğretmenler, öğrencilerin başarılı olacağına inanırlar. & & & & & \\
\hline 3 & Öğretmenler, öğrencileri cesaretlendirirler. & & & & & \\
\hline 4 & Öğretmenler, öğrencilere karşı olumlu davranış gösterirler. & & & & & \\
\hline 5 & Öğretmenler, öğrencileri güvende hissettirirler. & & & & & \\
\hline 6 & Çalışmalarda başarılı olan öğrenciler alkışlanır. & & & & & \\
\hline 7 & Etkinliklerde öğrenciler arasında işbirliği vardır. & & & & & \\
\hline 8 & Öğrenciler etkinliklerde birlikte hareket edebilirler. & & & & & \\
\hline 9 & Öğrenciler birbirlerini destekler. & & & & & \\
\hline 10 & Öğrenciler derslerde yardımlaşabilirler. & & & & & \\
\hline 11 & Sınıfta, öğrencileri motive edici afişler, posterler vb. vardır. & & & & & \\
\hline 12 & Sınıfta, öğrencileri cesaretlendirici görsel ögeler vardır. & & & & & \\
\hline 13 & Derslerde oyunlara yer verilir. & & & & & \\
\hline 14 & Öğretmenler, derslerde merak uyandıııı etkinlikler yaparlar. & & & & & \\
\hline 15 & Öğretmenler, öğrencilerin birlikte eğleneceği etkinlikler yaptırırlar. & & & & & \\
\hline 16 & Sinıfta rahat bir ortam vardır. & & & & & \\
\hline 17 & Sınıf, rahat ders çalışmaya uygundur. & & & & & \\
\hline 18 & Sınıf atmosferi öğrencileri rahatlatır. & & & & & \\
\hline 19 & Öğrenciler, sınıfta uyum içerisindedirler. & & & & & \\
\hline 20 & Sınıfta ihtiyaç olduğunda kullanılan renkli kalemler vardır. & & & & & \\
\hline 21 & Sınıfta ihtiyaç olduğunda başvurabilecek kitaplar vardır. & & & & & \\
\hline 22 & Sınıfta renkli araç ve gereçler vardır. & & & & & \\
\hline 23 & Sınıfta çalışılan konuyla ilgili araç ve gereçler vardır. & & & & & \\
\hline 24 & Sınıf kapısı süslüdür. & & & & & \\
\hline 25 & Ders esnasında rahatlatıcı müzik çalınır. & & & & & \\
\hline 26 & Sınıfta ders çalışırken odaklanmaya yardımcı olan müzik çalınır. & & & & & \\
\hline
\end{tabular}




\section{Development Study of Quantum Learning Environment Scale}

\author{
Res.Assist.Dr. Mehmet Altın \\ Aydın Adnan Menderes University-Turkey \\ mehmet.altin@adu.edu.tr
}

Prof.Dr. Asuman Seda Saracaloğlu

Aydın Adnan Menderes University-Turkey

sedasaracal@gmail.com

\begin{abstract}
Quantum learning was defined as an interactional combination of theories and approaches whose success has been proven in instruction. It is considered important to arrange learning environments in accordance with the quantum learning model. In the study, it was targeted to develop a scale able to measure the extent to how much the environment of any class was suitable to the environment of quantum learning model. An item pool related to the quantum learning environment was formed by reviewing the literature and by using the codes obtained from the examination of the qualitative data. Quantum Learning Environment Scale consisting of 6 dimensions and 26 items emerged at the end of the reliability and validity analyzes performed on the item pool. RMSEA value of the scale is .04, CFI value is .93, IFI value is .93 and SRMR value is .049. The reliability coefficient obtained for the whole scale is .93 .
\end{abstract}

Keywords: Learning environment, Quantum learning, Scale development

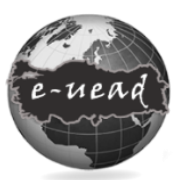

E-International Journal of Educational Research, Vol: 11, No: 2, 2020, pp. 35-49

DOI: 10.19160/ijer.742471

\section{Suggested Citation:}

Altın, M. \&. Saracaloğlu, A. S. (2020). Development Study of Quantum Learning Environment Scale, E-International Journal of Educational Research, Vol:11, No: 2, 2020, pp. 35-49, DOI: 10.19160/ijer.742471 


\section{EXTENDED ABSTRACT}

Problem: Nowadays, in order to increase the number of individuals who have the skills to reach information more rapidly and effectively and who use these skills in different areas throughout their lives, more studies have been conducted on the learning models that give importance to the learner during the education (Hanbay, 2009). The importance of learning models in the primary and secondary education levels at which individuals' cognitive, affective and psycho-motor skills are developing is quite significant. One of the models that can be used in different education levels is the quantum learning model.

The word of quantum was defined as energy block/pack at the researches on the black body radiation. Quantum was suggested as the interaction making energy to transform into light. Quantum learning is depicted as an interactional combination of theories and approaches whose success has been proven in instruction (DePorter and Hernacki, 1992). Quantum theory took place as scientific philosophy in the curriculum by a change considered as a reform in Turkey (Ekici, 2013). Thus, the curriculum grounded on quantum theory purposed to educate students able to think holistically, critically and creatively and who have multiple points of view. Thus, it is considered important to arrange learning environments in accordance with the quantum learning model. In the study, it was targeted to develop a scale able to measure the extent to how much the environment of any class was suitable to the environment of quantum learning model.

In quantum learning, approaches that attract the attention of learners and that give them a sense of trust have an important place. For quantum learning, a suitable environment should be created both physically and emotionally. The approaches used in effective classroom management, attention collection techniques and motivation for the effective participation of the learners in learning activities are variables around quantum learning environment. (Deporter ve Hernacki, 1992; Given ve Deporter, 2015).

Method: In the study conducted in the 2017-2018 academic year, 36 students attending at the 7th grade were included to prepare item pool, 28 students at the 7th grade attended to pilot and 476 students at the 7th grade attended to validity study. Actions suggested by DeVellis (2014) were taken in preparing the scale. Preparation of the item pool, obtaining expert opinion for scope validity, trial application, construct validity and reliability analyzes were respectively performed in the process of the development of the scale.

During the implementation of the curriculum which was organized in accordance with the quantum learning model in the seventh grade of a secondary school in the middle socio-economic level in Aydin province, data were collected with a diversification strategy. The diversification strategy is a set of efforts to increase the credibility of research results using different data sources, different data collection and analysis methods (Ylldirım and şimşek, 2008). Observation, document review and interview were used as data collection techniques. As the qualitative data about the curriculum implemented to 7 th grade learners appropriate for the quantum learning model were analyzed, the data on environment dimension of the quantum learning were obtained. A pool of 79 items was created for the quantum learning environment as a result of the codes obtained from the qualitative data and the literature review. The pool was sent to ten experts to get their opinions for the purpose of ensuring the scope validity. The item pool was formed according to the feedback received from the experts. Then, pilot scale was applied to 28 students attending to the 7 th grade of a middle school.

Findings, Discussion and Results: Validity and reliability studies were conducted after the pilot implementation. At first, exploratory factor analysis was applied in the construct validity study. In exploratory factor analysis, Quantum Learning Environment Scale consisting of 6 dimensions and 26 items has been reached as a result of rotations, extraction and addition processes. In the correlation matrix between the items, it is seen that the items with acceptable relationship ( $r>$.3) are quite high. In addition, the determinant of the matrix is .002, which suggests that factor 
analysis is possible (Determinant $>$.0001). Multiple interferences between substances $(r>.9)$ are not observed.

Confirmatory factor analysis was performed to test the data fit of the model obtained as a result of exploratory factor analysis. AMOS program was used for analysis. Since the relationship between the dimensions in the model is not greater than .9, the assumption of not having multiple connections between variables is met (Tabachnich and Fidell, 2015). At the end of the analysis, it was observed that the model is in good fit.

The Cronbach alpha coefficient of the data was calculated to determine the reliability of the developed scale. The reliability coefficient obtained for the whole scale is .86 . The reliability coefficient of the sub-dimensions of the scale are .77 for the-teacher, .72 for the solidarity dimension, .67 for the motivation dimension, .97 for the comfort/fit dimension, .61 for the tool/material dimension and .61 for the aesthetic dimension. As a result of the reliability analysis, it was found that internal consistency was high both in the whole scale and in the interdimensional consistency.

Quantum Learning Environment Scale consisting of 6 dimensions and 26 items emerged at the end of the reliability and validity analyzes performed on the item pool. There is no negative expression in the scale. Therefore, there is no need for reverse coding in the analysis. The highest score in the scale is 130 while the lowest score in the scale is 26. Higher scores mean that the classroom environment is suitable for the quantum learning environment.

On the developed scale, data were collected from the 7th grade students at secondary school level. It is advisable for researchers who will research at different levels to adapt the scale to those stages. This research is a scale development study, and only the validity and reliability of the scale was obtained. By using this scale as a data collection tool in different studies, descriptive studies can be conducted to determine to what extent the 7th grade level is close to the quantum learning environment. 